\title{
III Congreso Latinoamericano y Caribeño de Ciencias Sociales, organizado por la Facultad Latinoamericana de Ciencias Sociales
}

Quito, 26-27 de agosto de 2015

Virginie Baby-Collin y Geneviève Cortes

\section{(2) OpenEdition}

12 Journals

\section{Edición electrónica}

URL: http://journals.openedition.org/bifea/7613

DOI: $10.4000 /$ bifea.7613

ISSN: 2076-5827

Editor

Institut Français d'Études Andines

Edición impresa

Fecha de publicación: 1 agosto 2015

Paginación: 304-309

ISSN: 0303-7495

\section{Referencia electrónica}

Virginie Baby-Collin y Geneviève Cortes, « III Congreso Latinoamericano y Caribeño de Ciencias Sociales, organizado por la Facultad Latinoamericana de Ciencias Sociales », Bulletin de l'Institut français d'études andines [En línea], 44 (2) | 2015, Publicado el 08 agosto 2015, consultado el 06 noviembre 2020. URL : http://journals.openedition.org/bifea/7613 ; DOI : https://doi.org/10.4000/ bifea. 7613

\section{(c) $(1)$}

Les contenus du Bulletin de l'Institut français d'études andines sont mis à disposition selon les termes de la licence Creative Commons Attribution - Pas d'Utilisation Commerciale - Pas de Modification 4.0 International. 


\section{CONGRESO LATINOAMERICANO Y CARIBEÑO DE CIENCIAS SOCIALES,}

ORGANIZADO POR LA FACULTAD LATINOAMERICANA DE CIENCIAS SOCIALES

Quito, 26-26 de agosto de 2015

El tercer Congreso Latinoamericano y Caribeño de Ciencias Sociales, organizado por la Facultad Latinoamericana de Ciencias Sociales, tuvo lugar los días 26-27 
y 28 de agosto de 2015 en la ciudad de Quito. La FLACSO es un organismo internacional creado en 1957, por iniciativa de la Unesco y algunos gobiernos de América Latina. El sistema cuenta con sedes, programas y proyectos académicos de posgrado en ciencias humanas y sociales, en Argentina, Brasil, Chile, Costa Rica, Cuba, Ecuador, El Salvador, España, Guatemala, Honduras, México, Panamá, Paraguay, República Dominicana y Uruguay, la sede de Quito siendo la más importante de Suramérica. El evento que agrupó alrededor de 1200 investigadores, académicos y estudiantes de América y Europa, tuvo por objetivo proporcionar una plataforma de encuentro y debate sobre los desafíos para la integración y concertación latinoamericana a partir de 18 ejes temáticos ${ }^{1}$ así como pasar revista al estado de la investigación sobre la realidad social, política y económica de la región. Si la mayoría de los ponentes procedieron de los países latinoamericanos, más de cien ponentes vinieron de América del Norte y de Europa, sobre todo de España (Universidades de Madrid, Barcelona, Salamanca, La Coruña, etc.), pero también de Francia22, Canadá, Estados Unidos, Reino Unido, Países Bajos, Alemania, Bélgica, etc.

Con la inauguración del congreso por los responsables institucionales el martes 25 por la noche, se dio la primera conferencia magistral de Aníbal Quijano. El renombrado sociólogo y teórico político peruano abrió los debates científicos retomando, desde una perspectiva histórica, uno de sus temas de predilección o sea la «colonialidad del poder» en América Latina, asociada a la dominación de la raza en todas las relaciones sociales. El tema está de actualidad en una región donde la fuerza de los movimientos sociales, indígenas, y el carácter inédito de los cambios políticos en los últimos diez años reconfiguran el panorama de las relaciones de poder y de las desigualdades. Anibal Quijano llama a una necesaria decolonialidad del poder, que tiene que pasar por una diversidad de epistemes alternativas de rebelión. Seis otras conferencias magistrales, con investigadores tanto en los campos de la Sociología y estudios de género, de los estudios políticos

1 Ciencia política, democracia e instituciones; Conflicto político, participación y Estado; Conocimiento, procesos culturales y transformaciones políticas; Economía del desarrollo y políticas públicas; Economías, migraciones y desigualdades globales, Economía política internacional del desarrollo; Epistemologías socioambientales; Estudios estratégicos, seguridad y conflicto; Género, subjetividades y ciudadanías; Medios y política; Movimientos sociales y Estado en América Latina; Políticas públicas comparadas; Políticas sociales Sujetos, historia, memoria y producción de saberes; Territorialidades rurales; Territorialidades urbanas; Transformaciones estatales, democracia, desigualdad y poder; Visualidad.

2 Se menciona la presencia de investigadores de varias instituciones francesas y varias disciplinas (Economía, Geografía, Ciencias Políticas, Sociología): Evelyne Mesclier (IRD- U. Paris 1); Geneviève Cortes (U. Montpellier 3); Virginie Baby Collin (U. Aix Marseille); Katy Liliana Pacheco Pena (U. Paris 1); Silvia Macedo (U. Paris Ouest Nanterre); Nancy Ochoa (U. Paris 10); Julie Carpentier (U. Paris 10); Jean-Luc Brackelaire (École Centrale Paris); Jean de Munck (École Centrale Paris); Ana Correa Gendrón (U. Paris 3 Sorbonne Nouvelle); Florence Pinton (AgroParisTech); Stéphen Rostain (U. Paris 10); Ana Torres (U. Paris 12); Matthieu Le Quang (U. Paris 8); Thais Nuñez Rocha (U. Paris 1); Meitner Cadena (U. Pierre et Marie Curie-Paris VI); Daniela Granda (U. Paris 3 Sorbonne Nouvelle); Katy Liliana Pacheco Pena (U. Paris 1); Silvia Macedo (U. Paris Ouest Nanterre La Défense); Dorothée Delacroix (U. Toulouse 2); Jean Lapeze (U. Grenoble 2); Polina Palash (U. Aix Marseille). 
como también del desarrollo en relación con el medio ambiente y territorio, constituyeron otros momentos fuertes del evento. No solo se organizaron 300 sesiones de trabajo siguiendo los 18 ejes temáticos, pero también eventos especiales, exposiciones de libros, mesas redondas o encuentros más informales y conviviales con proyección de documentales al aire libre frente al edificio principal de la Flacso.

El tema de la muestra de cine, Globalización y desigualdades sociales, dio a ver nueve obras de diferentes formatos, tanto documentales como ficciones, producciones universitarias de menor escala (documentales sobre la migración ecuatoriana al exterior vista desde el punto de vista de los que se quedaron en el país de origen —en los documentales Migra Fútbol y El mismo sueño— ambos producidos por la FLACSO Ecuador) así como producciones reconocidas internacionalmente (La Jaula de Oro, de Diego Quemada Diez, ficción mexicana de 2013 sobre la huida de tres jóvenes guatemaltecos hacia Estados Unidos, o La Sal de la Tierra, de Wim Wenders y Juliano Ribeiro Salgado, 2014). Las obras presentadas, alrededor de la complejidad del fenómeno de la migración internacional, de las luchas y desafíos ambientales, denuncian las desigualdades sociales dentro del proceso de globalización y dialogan con varios ejes temáticos del programa, como el relativo a Economías, migraciones y desigualdades sociales, sobre el cual, para entrar más en detalles en una de las temáticas principales del congreso, proponemos ahora un focus.

Con 15 mesas redondas y un evento especial coorganizado con Clacso y Migrared, que contó también con el apoyo del Instituto Francés de Estudios Andinos (UMIFRE 17, CNRS-MAEDI), este eje permitió escuchar alrededor de 65 ponencias, dentro de las cuales 45 sobre temáticas migratorias, lo cual es revelador de la actualidad del tema hoy en día en la región. Otras temáticas segundarias en este eje fueron dedicadas a las economías populares y asociativas, al trabajo informal en sus debates actuales y a las reformas universitarias en sus relaciones con economía y Estado en Ecuador y América Latina. Hubo una gran presencia de ponentes internacionales, con 22 ecuatorianos, 32 provenientes de otros países latinoamericanos (Brasil, Argentina, Colombia, Chile, America Central, y una fuerte presencia de Mexicanos -14 ponentes-), 3 de Estados Unidos y 13 de Europa (España y Francia siendo los dos países más representados).

Se escucharon trabajos sobre temáticas clásicas, como la del capitalismo y de la precariedad en las migraciones laborales, que fue reactivada a través de los casos de las fronteras norte y sur de México y también, de manera muy original, con un análisis de las dinámicas históricas de los circuitos migratorios a partir del sur del Ecuador en el siglo XX, en la presentacion de los resultados de la tesis doctoral de María Mercedes Eguiguren (Universidad Católica de Louvain en Bélgica y FLACSO Ecuador).

Se organizaron sesiones sobre temas relevantes en la actualidad, tales como Niñez en migración: tránsito, trabajo infantil y respuestas institucionales (con contribuciones de México y América Central, donde la problemática es bastante fuerte, pero con un enfoque también histórico sobre el trabajo infantil durante el programa bracero), o Crisis y nuevas migraciones españolas a América Latina, donde se 


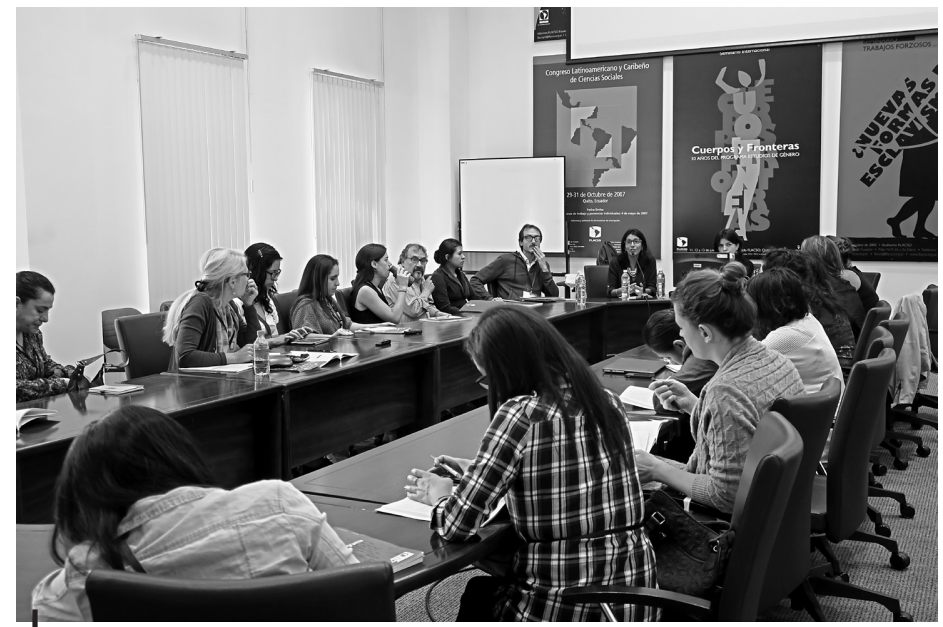

Evento especial Movilidades y espacios, nuevos desafíos y viejos dilemas en el estudio de las migraciones latinoamericanas, organizado por Clacso y Migrared con el apoyo del IFEA, en el salón de afiches de la FLACSO

Al fondo, con el micrófono, Gioconda Herrera, subdirectora académica de la FLACSO y responsable del eje Migraciones y sociología de género de la FLACSO Ecuador. A su derecha, Sergio Caggiano (CIS-Conicet/ IDES), a su izquierda, Carolina Stefoni (Universidad Alberto Hurtado)

enfatizó el proceso creciente de salida de españoles después de la crisis de 2008, muchos de ellos calificados, hacia el continente latinoamericano. Este movimiento fue analizado en términos de circulación migratoria (por ejemplo a través de las dinámicas educativas entre España y Ecuador — programa de investigación de la Flacso presentado por Carmen Gómez Martín y Cristina Vega-), o del exilio. Otro tema fuerte de la actualidad fue el retorno de los migrantes en contexto de crísis en Europa. Más alla de la sesión La experiencia del retorno en Ecuador y América Latina (con ponencias sobre Ecuador, México, Guatemala), esta problemática estuvo presente en muchas discusiones de otras mesas del eje temático. Cabe resaltar por ejemplo el trabajo de Liliana Rivera Sánchez, del Colegio de México, quien insistió sobre la diversidad de los procesos y de los actores del retorno, y estudió los procesos de delocalización/relocalización que implican el retorno, a través de un ensamblaje complejo de experiencias diversas de movilidad y anclaje que no necesariamente conducen a un proceso de reinserción, a partir del caso mexicano (ciudad de Nezahuatcoyotl). En la discusión general que animó Gioconda Herrera, directora del eje de investigación sobre «Migraciones y género» en la FLACSO Ecuador, en el evento especial Movilidades y espacios, nuevos desafíos y viejos dilemas en el estudio de las migraciones latinoamericanas, se relativizó el proceso del retorno, que se ve como parte inherente del proyecto migratorio y de dinámicas circulatorias más que el final de un ciclo. En este sentido, investigaciones recientes muestran que el retorno es una mera etapa 
que puede llevar a nuevos despliegues hacia otros destinos (Geneviève Cortes y Virginie Baby Collin). Dentro de la experiencia del retorno, varios ponentes ilustraron la diversidad de las situaciones, entre los retornos preparados y las expulsiones del territorio de destino (sea desde Estados Unidos o desde España), los retornos emprendedores y exitosos de unos y el sentimiento de fracaso y de desajuste de otros.

La toma en consideración del espacio en la migración fue uno de los temas relevantes, tanto en el evento especial como en otras sesiones. Más allá del paradigmo transnacional, se observó el papel de unos microlugares territorializados por migrantes en búsqueda de trabajo en Chile (Carolina Stefoni, Universidad Alberto Hurtado), se planteó la necesaria articulación entre posiciones y movimientos en el análisis de las prácticas espaciales de los migrantes (Sergio Caggiano, CISConicet/IDES), o se discutió el desafío metodológico del multisituado en las migraciones (Virginie Baby-Collin, Geneviève Cortes). Se presentaron nuevos proyectos originales con enfoques multisituados, como la investigación doctoral de Polina Palash (Universidad Aix Marseille), quien analiza los arreglos formales e informales de protección social transnacional de los migrantes ecuatorianos cuyas familias viven entre Europa y el país de origen.

Las diferencias de experiencias de la migración fueron analizadas también en sesiones que propusieron un análisis a partir de los cuerpos y de las diferencias de género (Género, cuerpo y experiencia migratoria en América Latina: entre la agencia y la subalternización; y Migraciones, sexualidades y las fronteras de la ciudadanía) o de las peculiaridades de los jóvenes indígenas. Una dirección de investigación analizó los impactos de las relaciones de género sobre la organización de las migraciones, así como, al revés, los efectos de la migración sobre las transformaciones de las relaciones de género. Es, una vez más, a través del retorno (forzado o voluntario) que se observan las recomposiciones de las relaciones de género, y los conflictos inherentes, a nivel de las parejas, de las familias, o de las comunidades rurales de retorno, como lo analiza Lucía Salomé Pérez Martínez (FLACSO Ecuador) con el caso de la provincia de Cañar en el sur de Ecuador, y otros en el caso mexicano. Desde los espacios de destino de la migración, Laura Oso (Universidade da Coruña) en el caso español y Martha Cecilia Ruiz Muriel (FLACSO Ecuador) en el caso del sur de Ecuador, analizan la manera cómo las mujeres migrantes invierten su «capital erótico» en trabajos sexuales, tanto en los clubs y pisos de servicio de Galicia como en prostíbulos y barras bares de la zona del Oro. Discuten las estrategias de las mujeres en el trabajo sexual visto como un medio de agencia, pero no siempre de empoderamiento.

La sesión sobre los jóvenes indígenas analizó cómo los jóvenes de primera o segunda generación recomponen sus identidades étnicas indígenas a través de las generaciones. Natalia Gavazzo (Universidad Nacional de General San Martín), observando jóvenes de origen boliviano en Buenos Aires, y Daniela Celleri (Universidad de Hanover), con jóvenes indígenas otavaleños migrantes en Bogotá desde las comunidades de origen, se ubican cada una a dos polos opuestos del circuito migratorio. Mientras que la primera demuestra la pluralidad de las 
referencias identitarias de los jóvenes, la segunda indica cómo la indianidad es un complejo lleno de tensiones y fracturas internas, con líneas de fragmentación de género y de clase social, más allá de los conflictos intergeneracionales.

Finalmente, un último eje dominante de los trabajos migratorios tuvo que ver con visiones más políticas, sea desde el punto de vista de la reflexión sobre las migraciones forzadas, internas o internacionales (a través de mesas sobre Viejas y nuevas formas de migración forzada en América Latina y el Caribe: retos para la integración social; Refugio y desplazamientos internos: violación de los derechos humanos y construcción de sujetos en las migraciones forzadas), o de las políticas migratorias en América Latina (Entre la aplicación del paradigma securitario y la construcción de espacios de integración regionales), sesión en la cual se abrió la discusión sobre la idea de ciudadanía latinoamericana a través de la libre movilidad de las personas.

A través de este zoom sobre un eje relevante del congreso, se reflejó a la vez el dinamismo de la investigación internacional sobre las multiples dimensiones del fenómeno migratorio, y las orientaciones transdisciplinares hacia temáticas novedosas. 